\title{
Use of mechanical activation in the processing of gold-bearing ores and anthropogenic materials
}

\author{
Natalia Litvinova ${ }^{1 *}$, Aleksandra Kopylova ${ }^{1}$, Valentina Stepanova ${ }^{1}$ and Hitachi Tatsumi ${ }^{2}$ \\ ${ }^{1}$ Mining Institute FEB RAS, 51 Turgenev st., Khabarovsk, 680000, Russia; \\ ${ }^{2}$ JEOL Ltd., 1-2 Musashino 3-Chome, Akishima, Tokyo 196-8558, Japan
}

\begin{abstract}
The results of experimental studies on the use of mechanical activation in the processing of ores and anthropogenic materials of the Far Eastern region are presented. The effectiveness of the use of electrophotoactivated solutions and complex reagents at the stage of mineral preparation has been established. Technological solutions have been proposed to reduce the loss of finely dispersed and chemically bonded gold during the processing of gold-bearing materials based on a directed change in the properties of the surface of minerals. The effectiveness of the use of the mechanochemical activation process for various aspects of the technological chain has been experimentally confirmed - a decrease in the sorption properties of materials, development of microcracks in oxidized ores for the penetration of leaching solutions into mineral aggregates, oxidation of the surface of primary ores, and removal of films from the mineral surface. Indicators of technological refractoriness of the studied ores and anthropogenic materials were revealed - a high proportion of chemically bound gold with atoms of basic and accessory mineral-forming elements, the presence of grains of the valuable component covered with oxide films, enclosed in carbonates, quartz and waste rock. The refractoriness of ores is confirmed by a high sorption capacity (the predominance of carbonaceous and clay matter), the presence of trace impurities in gold $(\mathrm{Sb}, \mathrm{As}, \mathrm{Cu}, \mathrm{Fe}, \mathrm{Hg})$, which increase the consumption of cyanide during leaching. The material composition is dominated by a significant amount of chemical elements - cyanosides, actively interacting with the main complexing agent of leaching solutions cyanide of alkali metals.
\end{abstract}

\section{Introduction}

The most hard to detect and to extract forms of noble metal mineralization are clustered atoms of valuable metals chemically bound to the atoms of the main and accessory mineralforming elements. To identify and extract such formations, it is necessary to use the processes that ensure the transformation of the crystal lattice of mineral concentrators with the movement of clusters of integral and defragmented particles to the surface of micro-

\footnotetext{
*Main author: nauka22@yandex.ru
} 
and nanocracks, pores, and their subsequent aggregation. The implementation of this condition can be carried out both by physical action on the crystal lattice of minerals, and by chemical means: using solutions containing active components that can penetrate into its inner layers [1-3]. One of the directions of intensification in the processing of mineral goldbearing mixtures of various genesis is the process of mechanical activation. Mechanical activation leads to a noticeable increase in the energy state of minerals and their reactivity due to the breaking of valence bonds, an increase in defectiveness and distortions of the crystal structure. When processing gold-bearing materials, the effectiveness of the process of directed change in the properties of minerals based on the mechanic activation of their surface was established for various aspects of the technological chain - to reduce the sorption properties of materials (the presence of carbonaceous and clay matter, etc.), to develop microcracks in oxidized ores for the penetration of leaching solutions into mineral intergrowths, oxidation of the surface of primary ores, removal of films on the mineral surface, etc. Foreign scientists have confirmed that the mechanical activation of minerals causes structural changes and new surface formations [4-6]. In addition, it has been proven that mechanically activated minerals have small crystallite sizes and a large number of grain boundaries, preparing more atoms ready for reaction [7]. As a result of research, it was found that mechanical activation not only contributes to the stabilization of homogeneity of the composition and an increase in the surface area of the material under study, but also leads to the destruction of the crystal structure $[8,9]$.

\section{Methodology of Research}

Sample preparation of the ore material was carried out using modern Fritsch equipment (Pulverisette 1 jaw crusher, Pulverisette 13 disk mill, Analysette 3 vibrating screen). Qualitative and abbreviated mineralogical analyzes for monofraction of noble metals were performed using microscopes Stemi 2000, Stereo Discovery V8 by ZEISS. Scanning electron microscopic study of the composition of gold grains from various types of ores, unloading the mill and middlings was carried out on a JEOL microscope (Japan) equipped with a JCM-6000 PLUS energy dispersive X-ray analyzer (Institute of Mining of the FEB RAS). A TOC-V (SHIMADZU) Total Carbon Analyzer was used to quantify total, organic and inorganic carbon. Quantitative analysis for gold and silver of the provided samples was carried out by the flame atomic absorption method after extraction with isoamyl alcohol (NSAM-131-C method) and NSAM-130-C method. The qualitative analysis of the starting materials and middlings was carried out using a Mobilab X-50 X-ray fluorescence analyzer. The spectral analysis of the V category of accuracy of the starting materials and enrichment products, the assessment of intermediate stages of technological tests were carried out using a Grand atomic emission multichannel spectrometer. The mechanical activation of materials was carried out using electrophotoactivated carbonate-cyanide and hypochloritechloride solutions, non-activated reagents - sodium hydroxide, sodium chloride, sodium carbonate, sodium bicarbonate, iodine, magnesium chloride, techrope, potassium stearate, bornyl acetate, PAV-1 complex reagent.

The object of research is stale cyanidation cakes of Pokrovsky mine gold processing plant, gold-bearing ores of the Albazinsky, Zolotorudny, Mnogovershinnoye fields, gravity tailings of the ferromanganese ore of the Poperechnoye deposit (hematite-magnetite and magnetite ore and host rocks (limestone, dolomite, carbonaceous shale)), ores of the oxidation zone of the Malmyzh field. 


\section{Results of Experimental Study}

The ore material of the Albazinsky deposit is characterized by gold-sulfide-quartz vein dissemination. The ore contains a carbonaceous-clayey substance, ore minerals are pyrite and arsenopyrite. A mineralogical analysis revealed the presence of finely disseminated gold in pyrite and arsenopyrite, gold in intergrowths (cyaninated), covered with oxide films and enclosed in carbonates, in quartz and waste rocks. The prevalence of the share of fine and finely dispersed gold over relatively coarse gold is characteristic. Trace impurities in gold are $\mathrm{Sb}, \mathrm{As}, \mathrm{Cu}, \mathrm{Fe}, \mathrm{Hg}$, increasing the consumption of cyanide during leaching. The refractoriness in gold for ores of the Mnogovershinnoye deposit is due to the presence of gold-bearing sulfides, the valuable component being with films and coatings, and an increased proportion of carbonaceous matter in the sample. Difficulties in relation to the process of leaching of gold from anthropogenic material (stale cakes of the ZIF-1 storage facility at Pokrovsky Rudnik JSC) are in the nanoscale form of grains of the valuable component. Research on ferromanganese ore was carried out using the material of gravity tailings of two types of ore (hematite-magnetite and magnetite) and different rocks (limestone, dolomite, coal shale). Research on "gravity gold" is reflected in [10-12]. In all studied samples, gold with a size below 100 microns predominates, the refractoriness of carbonaceous shales in relation to the standard cyanidation process, problems with a high iron content in samples are evident. From the standpoint of technological persistence during leaching, oxidized ores of the Malmyzh field are characterized by the absence of the main complicating factors: residual sulfide minerals and sorption-active carbonaceous matter. Gold in the oxidized ores of the Malmyzh deposit is mainly represented by a dispersed and encapsulated form, concentrated mainly in minerals-carriers permeable to leaching solutions. There is a significant amount of chemical elements-cyanosides (iron and copper), actively interacting with the main complexing agent of leaching solutions - cyanide of alkali metals.

Table 1 shows the results of analytical studies on gold content and its recovery into concentrate using the standard technology and the process of mechanical activation.

As a result of four-stage leaching with an active chloride solution of ferromanganese ores of the Poperechnoye field, high rates of gold recovery into a productive solution were obtained, up to $96 \%$ (with standard cyanidation, 18\%). On average, for all types, loss reduction is up to $60 \%$.

The mechanical activation of samples of stale cyanidation cakes from the Pokrovsky mine, in addition to regrinding relatively large mineral particles, ensured the formation of microcracks in quartz and adularia grains and the opening of dispersed nanosized gold. According to the results of leaching samples from different horizons, the gold content in the liquid phase increases in proportion to the duration of the mechanochemical activation of the pulp treated on the basis of an active carbonate-cyanide solution for all samples. Compared with the variant of mechanical activation in an aqueous medium, the gold content increased 3 times.

One of the directions of experimental research in the Laboratory for concentration at the Institute of Mining is the mechanical activation of the mineral mass using complex reagents in the sorption leaching of ores. Experimental studies on the use of preliminary mechanochemical activation of the Mnogovershinnoye field ore showed that the introduction of effective complex additives during ore grinding with subsequent cyanidation of the crushed samples made it possible to increase the recovery of gold into a productive solution. The research results are presented in table 2. 
Table 1. Results of analytical studies on gold content and its recovery into concentrate using the standard technology and using the process of mechanical activation

\begin{tabular}{|c|c|c|c|}
\hline \multirow[b]{2}{*}{ Name of field, type of ore } & \multirow[b]{2}{*}{ Main composition and size of the valuable component } & \multicolumn{2}{|c|}{ Recovery, \% } \\
\hline & & $\begin{array}{l}\text { Standard } \\
\text { technology }\end{array}$ & $\begin{array}{l}\text { Using mechanical } \\
\text { activation }\end{array}$ \\
\hline $\begin{array}{l}\text { Poperechnoye, ferromanganese } \\
\text { limestone, } 0.68 \mathrm{~g} / \mathrm{t}\end{array}$ & $\begin{array}{l}\text { Gold with silver inclusions of dolomite and pyroxenes; gold } \\
\text { with inclusions of galena, lead and rock-forming minerals, 70- } \\
75 \text { microns }\end{array}$ & $\begin{array}{l}14.71 \\
\text { leaching }\end{array}$ & $\begin{array}{c}88.24 \\
\text { leaching }\end{array}$ \\
\hline $\begin{array}{l}\text { Poperechnoye ferromanganese, } \\
\text { magnetite ore, } 1.02 \mathrm{~g} / \mathrm{t}\end{array}$ & $\begin{array}{l}\text { Pure gold; gold with an admixture of silver in intergrowth with } \\
\text { magnomagnetite, quartz and pyroxenes; gold with chloritoid; } \\
\text { gold with an admixture of silver, cadmium and aluminum; gold } \\
\text { with inclusions of quartz and vapor-generating minerals; gold } \\
\text { with an admixture of silver and aluminum, 40-200 microns }\end{array}$ & $\begin{array}{l}17.65 \\
\text { leaching }\end{array}$ & $\begin{array}{l}96.76 \\
\text { leaching }\end{array}$ \\
\hline $\begin{array}{l}\text { Poperechnoye ferromanganese, } \\
\text { dolomitized limestone, } 1.175 \mathrm{~g} / \mathrm{t}\end{array}$ & $\begin{array}{l}\text { Gold with an admixture of silver; gold in intergrowth with rock- } \\
\text { forming minerals, } 50-110 \text { microns }\end{array}$ & $\begin{array}{c}60.19 \\
\text { leaching }\end{array}$ & $\begin{array}{c}91.49 \\
\text { leaching }\end{array}$ \\
\hline $\begin{array}{l}\text { Poperechnoye ferromanganese, } \\
\text { hematite-magnetite ore, } 1.45 \mathrm{~g} / \mathrm{t}\end{array}$ & $\begin{array}{l}\text { Gold with an admixture of silver; gold in intergrowth with rock- } \\
\text { forming minerals, } 30-50 \text { microns }\end{array}$ & $\begin{array}{c}8.09 \\
\text { leaching }\end{array}$ & $\begin{array}{c}93.11 \\
\text { leaching }\end{array}$ \\
\hline $\begin{array}{l}\text { Poperechnoye ferromanganese, } \\
\text { carbonaceous shale, } 0.63 \mathrm{~g} / \mathrm{t}\end{array}$ & Gold with admixtures of silver, iron and lead, 50 microns & $\begin{array}{c}7.94 \\
\text { leaching }\end{array}$ & $\begin{array}{c}54.6 \\
\text { leaching }\end{array}$ \\
\hline Gold ore field, $6.52 \mathrm{~g} / \mathrm{t}$ & $\begin{array}{l}\text { Gold with dimensions, flattened with smooth edges; on the } \\
\text { surface, there are deposits with iron hydroxides, clay fillers; } \\
\text { there are also clean grains. The color is yellow, light. Fine gold } \\
\text { has a thin-plate appearance. Plates with hooked processes, with } \\
\text { a smooth, shiny surface. There are wire-like discharge, lumpy- } \\
\text { rounded grains, of a crystalline appearance. } 0.25 \text { to } 0.57 \mathrm{~mm}\end{array}$ & $\begin{array}{c}30 \\
\text { leaching }\end{array}$ & $\begin{array}{c}73 \\
\text { leaching }\end{array}$ \\
\hline $\begin{array}{l}\text { Cakes of the storage facility Mill-1 of } \\
\text { Pokrovsky Rudnik JSC, } 0,35 \mathrm{~g} / \mathrm{t}\end{array}$ & Gold particle size in cyanidation cakes $<100 \mathrm{~nm}$ & $\begin{array}{c}<30 \\
\text { leaching }\end{array}$ & $\begin{array}{c}72 \\
\text { leaching }\end{array}$ \\
\hline $\begin{array}{l}\text { Malmyzh copper-gold deposit, } \\
\text { oxidation zone, } 0.8 \mathrm{~g} / \mathrm{t}\end{array}$ & $\begin{array}{l}\text { Gold with an uneven rough surface, hooked edges, light yellow. } \\
\text { From } 170 \text { to } 700 \text { micrometers - consists of individual crystals of } \\
\text { a cubic and prismatic appearance, lamellar packets and irregular } \\
\text { grains. The composition of gold is quite stable - with a silver }\end{array}$ & $\begin{array}{c}80 \\
\text { leaching }\end{array}$ & $\begin{array}{l}94 \\
\text { leaching }\end{array}$ \\
\hline
\end{tabular}




\begin{tabular}{|c|c|c|c|}
\hline & content of up to $17-26 \%$ by weight (electrum) & & \\
\hline Albazinskoe, $24 \mathrm{~g} / \mathrm{t}$ & $\begin{array}{l}\text { Gold finely disseminated in pyrite and arsenopyrite, in } \\
\text { intergrowths (covered with oxide films and enclosed in } \\
\text { carbonates, in quartz and waste rock (particle size less than } \\
0.001 \mathrm{~mm} \text { ). Trace impurities in gold: } \mathrm{Sb}, \mathrm{As}, \mathrm{Cu}, \mathrm{Fe}, \mathrm{Hg}\end{array}$ & $\begin{array}{c}76 \\
\text { floatation }\end{array}$ & $\begin{array}{c}84 \\
\text { floatation }\end{array}$ \\
\hline Mnogovershinnoye, $6 \mathrm{~g} / \mathrm{t}$ & $\begin{array}{l}\text { Free gold, intergrowths with quartz. The color is eolith yellow } \\
\text { and light yellow, the edges and surface are uneven. Basically, } \\
\text { gold is very small (less than } 0.1-0.05 \mathrm{~mm} \text { ) up to dusty. The } \\
\text { forms of gold grains are very diverse, rarely cubic crystals. The } \\
\text { surface is very uneven with sharp ridges and depressions. }\end{array}$ & $\begin{array}{c}90 \\
\text { leaching }\end{array}$ & $\begin{array}{c}98 \\
\text { leaching }\end{array}$ \\
\hline
\end{tabular}

Table 2 - Results of studies on sorption extraction of gold from gold-bearing ore of Mnogovershinny MPP (consumption $100 \mathrm{~g} / \mathrm{t}$ )

\begin{tabular}{|c|c|c|}
\hline No. & Grinding medium type & Au recovery, \% for coal \\
\hline 1 & Distilled water & 90.86 \\
\hline 2 & $\mathrm{NaOH}$ & 95 \\
\hline 3 & Arabinogalactan & 96.29 \\
\hline 4 & Stearate $\mathrm{K}$ & 96.80 \\
\hline 5 & $\mathrm{Na}_{2} \mathrm{CO}_{3}$ & 97.0 \\
\hline 6 & $\mathrm{NaHCO}_{3}$ & 94.71 \\
\hline 7 & Bornylacetate & 98.27 \\
\hline
\end{tabular}


According to the research results, it can be noted that the introduction of reagent complexes at the stage of ore treatment reduces the intrinsic sorption capacity of the ore associated with the presence of carbonaceous, clayey matter, chemical elements-cyanosides and helps to reduce gold losses.

Agitation leaching of gold from oxidized ore of the Malmyzh field was carried out according to different reagent schemes. The first reagent scheme for leaching gold included the treatment of ore activated in electrochemical and photochemical reactors with a peroxide-carbonate solution, followed by leaching of gold with an ammonium-cyanide solution. The second scheme included preparation for leaching of ore with active peroxidesulfuric acid solutions, followed by leaching of gold with solutions with cyanide and chloride reagent base. It has been found that the highest rate of gold recovery into the productive solution (94\%) in the agitational leaching option is provided by the chloride scheme with peroxide-sulfuric acid preparation of the ore (compared to $80 \%$ for the cyanide scheme).

\section{Conclusion}

Based on the studies carried out, it can be concluded that it is advisable to use the mechanical activation process for various aspects of the technological chain - to reduce the sorption properties of materials (the presence of carbonaceous and clay matter, etc.), to develop microcracks in oxidized ores for the penetration of leaching solutions into mineral aggregates, surface oxidation primary ores, removal of films from the mineral surface, etc. The technological refractoriness of modern ore and technogenic materials requires a directed change in the surface properties of minerals containing noble metals, an increase in the reactivity of the mineral mass.

The use of the process of mechanochemical activation of mineral mixtures of various genesis helps to reduce the loss of finely dispersed gold during leaching and flotation concentration. It has been experimentally proven that the extraction of gold into a productive solution with preliminary mechanical activation of the ore using an active chloride solution in the leaching of ferromanganese ores of the Poperechnoe field is up to $96 \%$ (with standard cyanidation, 18\%). In agitational leaching of oxidized ore from the Malmyzh field, the extraction of gold into a productive solution (94\%) is provided by a chloride scheme with peroxide-sulfuric acid preparation of the ore (compared to $80 \%$ for a cyanide scheme).

\section{Acknowledgment}

Research was supported by scientific grant "Increasing the complexity of the use of mineral raw materials of various genesis on the basis of its systemic mineralogical and technological assessment and a differentiated approach to determining the content of precious metals by their modes of occurrence" is provided by the Government of Khabarovsk Territory (59 C, 21.08.2020). The financial support of the Government of Khabarovsk Territory is granted under the program "On the provision of grants in the form of subsidies from the regional budget for the implementation of projects in the field of scientific research in natural, technical, humanitarian and social sciences".

Chemical analysis of mineral raw material and leaching pregnant solutions were carried out on the basis of the Center for Collective Use of the Khabarovsk Federal Research Center FEB RAS. 


\section{References}

1. A.G. Sekisov, A.Yu. Lavrov, A.V. Rasskazova, Photochemical and electrochemical processes in geotechnology (2019)

2. A.G. Sekisov, A.Yu. Lavrov, Yu.S. Shevchenko, D.V. Manzyrev, A.A. Petukhov, T.G. Konareva, Bulletin of ChitGU, 80, 34-42 (2012)

3. A.G. Sekisov, A.I. Trubachev, T.G. Konareva, Gold mining industry, 51 (2012)

4. $\quad$ B.N. Akhgar, P. Pourghahramani, Hydrometallurgy, 83-87 (2015)

5. Xing-fu Zheng, Si-tingCao, Zhen-yuan Nie, Jian-hua Chen, Wei-bo Ling, Li-zhu Liu, Xuan Pan, Hong-ying Yang, Jin-lan Xia, Min. Eng., 106-209 (2020)

6. $\quad$ E. Godočíková, P. Baláž, Z. Bastl, L. Brabec, Appl. Surf. Sci., 36-47 (2002)

7. M. Zdujić, Č. Jovalekić, Lj. Karanović, M. Mitrić, D. Poleti, D.Skalaf, Materials Science and Engineering: A, 1, 109-117 (1998)

8. G. Kozhina, S. Estemirova, N. Pechishcheva, A. Murzakaev, E. Vovkotrub, M. Skrylnik, K. Shunyaev, Advanced Powder Technology, 4, 1202-1212 (2017)

9. $\quad$ F.Kh. Urakaev, V.V. Boldyrev, Powder Technology, 1-2, 93-107 (2000)

10. V.G. Kryukov, N.M. Litvinova, N.A. Lavrik, V.F.Stepanova, Concentration of ores, 370, 42-48 (2017)

11. A.I. Khanchuk, I.Yu. Rasskazov, V.G. Kryukov, N.M. Litvinova, B.G. Saksin, DAN, 470, 1-3, (2016)

12. V.G. Nevstruev, N.M. Litvinova, N.V. Berdnikov V.F. Stepanova, Mining Information and Analytical Journal, 486-492 (2016) 